\title{
Battered Women's Compliance-Gaining Strategies as a Function of Argumentativeness and Verbal Aggression
}

\author{
Jill E. Rudd \\ Cleveland State University, J.RUDD@csuohio.edu \\ Patricia A. Burant \\ Michael J. Beatty
}

Follow this and additional works at: https://engagedscholarship.csuohio.edu/clcom_facpub

Part of the Gender, Race, Sexuality, and Ethnicity in Communication Commons, and the Interpersonal and Small Group Communication Commons

How does access to this work benefit you? Let us know!

\section{Publisher's Statement}

This is an Accepted Manuscript of an article published by Taylor \& Francis in Communication Research Reports in 06/1994, available online: http://www.tandfonline.com/10.1080/ 08824099409359936.

\section{Recommended Citation}

Rudd, Jill E.; Burant, Patricia A.; and Beatty, Michael J., "Battered Women's Compliance-Gaining Strategies as a Function of Argumentativeness and Verbal Aggression" (1994). Communication Faculty Publications. 57.

https://engagedscholarship.csuohio.edu/clcom_facpub/57

This Article is brought to you for free and open access by the School of Communication at EngagedScholarship@CSU. It has been accepted for inclusion in Communication Faculty Publications by an authorized administrator of EngagedScholarship@CSU. For more information, please contact library.es@csuohio.edu. 


\title{
Battered Women's Compliance-Gaining Strategies as a Function of Argumentativeness and Verbal Aggression
}

\author{
Jill E. Rudd \\ Cleveland State University \\ Patricia A. Burant \\ Cleveland State University \\ Michael J. Beatty \\ Cleveland State University
}

In recent years, communication scholars have begun to examine communication-based factors in spouse abuse (Chandler, 1986; 1988; Infante, Chandler, \& Rudd, 1989; Infante, ChandlerSabourin, Rudd, \& Shannon, 1990; Rancer \& Niemasz, 1988). Infante, Chandler-Sabourin, Rudd, and Shannon (1990) examined the types of verbally aggressive messages that abusive couples used prior to violent acts. Their findings suggest that violent couples use different messages than do nonviolent couples. Infante and his colleagues (1989) advanced an Argumentative Skills Deficiency Model of Interspousal Violence (ASD), which holds that husbands and wives involved in violent marriages are less argumentative and more verbally aggressive than nonviolent couples.

Research indicates that message selection is, in part, a function of trait verbal aggression (Boster \& Levine, 1988; Infante, Trebing, Shepherd, \& Seeds, 1984; Infante \& Wigley, 1986) and argumentativeness (Boster, Levine, \& Kazoleas, 1993; Infante \& Rancer, 1982; Infante, Trebing, Shepherd, \& Seeds, 1984; Rancer, Baukus, \& Infante, 1985; Rancer \& Infante, 1985). Moreover, scholars implicate both variables in compliance-gaining strategy choice (Boster, Stiff, \& Reynolds, 1985; Infante, Anderson, Martin, Herington, \& Kim, 1989). Insofar as the connections among verbal aggression, argumentativeness and compliance-gaining strategies can be extended to interspousal contexts, the ASD model perspective of interspousal violence can be explicated with greater specificity. This study examined compliance-gaining strategy choice as a possible influence on violent behavior. As a starting point, two research questions were advanced. 
RQ 1: What compliance-gaining strategies do battered women report using in disputes that result in violence?

If a common pattern of responses is observed, it would provide insight regarding communication antecedents to physical aggression, at least at the descriptive level.

RQ 2: Are these strategies related to battered women's verbal aggression and argumentativeness?

The relationship of strategy use to verbal aggression and argumentativeness would extend the ASD model in several important ways. First, a connection between argumentativeness and types of strategy reported might indicate skill deficiency on the partner's part. Second, a relationship with verbal aggression might indicate a predisposition to employ counterproductive or ineffective strategies. Of course, the specific theoretic nature of such relationships depends on both their direction and magnitude.

Following this theoretical perspective, the present study extends the study of abuse by examining self-reported compliance-gaining strategies use in their most recent dispute that ended in violence.

\section{METHOD}

\section{Participants}

The participants in this study were 115 abused women who were seeking refuge from abusive spouses in temporary shelters for battered women. The shelters were located in a midwestern metropolitan area. Data were collected by the researchers over a period of four months. On the days researchers were granted access to the shelters, all women in residence were asked to participate. All residents participated. Participation was on a volunteer basis and confidentiality guaranteed. Women were told that the questionnaire was part of a study investigating the communication behaviors of couples. The participants were of diverse backgrounds, including 45 Caucasians, 58 African-Americans, 8 Hispanics, and 2 "other." The level of education for the participants was $9.8 \%$ grade school; $47.3 \%$ high school; $6.3 \%$ technical school; $30.4 \%$ some college; $4.5 \%$ college graduate; and $1.8 \%$ post graduate work. The majority of respondents $(92.2 \%)$ total family income was $\$ 29,999$ or less, with $56.3 \%$ earning $\$ 9,999$ or less. The sample included 33 employed and 77 unemployed women. The sample also included nine women who were pregnant. The age range of the participants ranged from 17 to 53 years of age. The majority of respondents $(92.5 \%)$ had between 2 to 4 children.

\section{Instruments}

Compliance-gaining strategies checklist. The compliance-gaining checklist was compiled from previous research. Participants were asked to report the frequency of strategy use by using the following scale of $1=$ never; $2=$ rarely; $3=$ occasionally; $4=$ sometimes; $5=$ often; and $6=$ a great deal. Specifically, the questionnaire was phrased, "When you and your partner disagree on an issue, how often do you use each of the following types of messages." Cronbach's coefficient alpha was .79 for this checklist.

The specific compliance-gaining typology used in this study was drawn from existing compliance-gaining research that focused on strategies used in interpersonal relationships. The use of compliance-gaining strategies checklist for this study differs from past studies relying on a checklist approach, in that this study is asking participants to recall an actual incident in their lives 
rather than a hypothetical situation. Although asking people about their intentions to behave in hypothetical situations has been challenged (Dillard, 1988) adults can provide relatively accurate reports of their recent behavior (Ericsson \& Simon, 1980). Supplemental analysis based on Burleson, Wilson, Waltman, Goering, Ely, and Whaley, (1988) criteria, indicated that participant reports of compliance-gaining strategies were not influenced by social desirability/appropriateness in the present study.'

Previous compliance-gaining research proposes that (1) in interpersonal relationships people use distinct types of strategies to resolve conflict (Cody, McLaughlin, \& Jordan, 1980; Falbo, 1977; Miller, Boster, Roloff, \& Seibold, 1977) and (2) the level of intimacy between individuals is a key factor in the selection of compliance-gaining strategies. Because this study is investigating the compliance-gaining strategies battered women reported using when engaged in conflict with their husbands, only compliance-gaining strategies that are specifically used in the interpersonal domain were included. Below is the strategy checklist that was distributed to participants as part of the questionnaire. $^{2}$ Sources for the strategies included research by: Cody, McLaughlin, and Jordan, 1980; Cody, McLaughlin, and Jordan, 1981; Falbo, 1977; Fitzpatrick and Winke, 1979; Johnson, 1976; Marwell and Schmitt, 1967; Wiseman and Schenck-Hamlin, 1981.

Ingratiation: I said or did something nice.

Promise: I promise to do something.

Debt: I reminded him of all the things I had done for him.

Esteem: I told him how good he would feel if he would agree with me or I suggested it was the right thing to do.

Allurement: I explained how agreeing would make other people respect him or what he is doing.

Aversive Stimulation: I did or said something that let him know how angry or hurt I was.

Threat: I threatened that I might do something that he would not want me to do.

Guilt: I made him feel guilty.

Warning: I warned him that other people would criticize him.

Altruism: I told him how helpful and generous it would be of him to agree.

Direct Request: I asked him simply to agree with my suggestion or solution.

Explanation: I tried to give him an explanation or reason for accepting my ideas.

Hint: I hinted at what I wanted without really asking him.

Deceit: I lied or tried to conceal the truth from him.

Empathetic: I discussed where we both agreed and where we disagreed in order to better understand how each of our ideas would work.

Bargaining: I offered to make a trade or strike a deal with him.

Other: I used some other way to get him to agree with me.

Verbal Aggressiveness Scale. The Verbal Aggressiveness Scale (Infante \& Wigley, 1986) was originally created as a 20 -item unidimensional scale. The revised 10 -item scale was used for this study (Appendix 1). Previous research supports the validity and reliability of the 10-item version (Infante, Chandler, Sabourin, Rudd, \& Shannon, 1990; Infante, Chandler, \& Rudd, 1989; Sabourin, Infante, \& Rudd, 1993). The scale assesses an individual's level of verbal aggressiveness. The coefficient alpha for this study was .74 for the individuals' self-report of verbal aggressiveness.

Argumentativeness Scale. The Argumentativeness Scale (Infante \& Rancer, 1982) was originally created as a 20 -item self-report scale to measure argumentativeness. The scale measures the motivation to approach arguments (ARGap) and the motivation to avoid arguments (ARGav). The 10-item version of the Argumentativeness Scale was used for this study (Appendix 1). Previous 
research supports the validity and reliability of the 10-item version (Infante, Chandler-Sabourin, Rudd, \& Shannon, 1990; Infante, Chandler, \& Rudd, 1989; Sabourin, Infante, \& Rudd, 1993). The scale was used to assess the abused women's level of argumentativeness. The coefficient alpha of the individuals' self-report of argumentativeness was .74 in this study.

\section{RESULTS}

The first research question regarding the compliance-gaining strategies that battered women reported using in violent disputes was addressed by calculating the reported frequency of use of the 16 strategies described previously. Table 1 lists in order of most frequent strategies battered women reported using in their disputes with their husband. Ingratiation, aversive stimulation, explanation, and promise were the most frequently used strategies. The least frequently used strategies were warning and altruism.

TABLE 1

Battered Women Compliance-Gaining Strategies-Means, Standard Deviation

\begin{tabular}{lcc}
\hline \multicolumn{1}{c}{$\begin{array}{c}\text { Compliance-Gaining } \\
\text { Strategies }\end{array}$} & Means & Standard Deviation \\
\hline Ingratiation & 4.104 & 1.423 \\
Aversive Stimulation & 4.000 & 1.451 \\
Explanation & 3.922 & 1.440 \\
Promise & 3.791 & 1.442 \\
Deceit & 3.504 & 1.769 \\
Empathetic & 3.354 & 1.652 \\
Hint & 3.316 & 1.620 \\
Debt & 3.209 & 1.614 \\
Guilt & 3.052 & 1.549 \\
Bargaining & 3.035 & 1.706 \\
Threat & 3.009 & 1.875 \\
Esteem & 3.009 & 1.490 \\
Direct Request & 2.852 & 1.517 \\
Allurement & 2.772 & 1.488 \\
Altruism & 2.664 & 1.455 \\
Warning & 2.400 & 1.532 \\
\hline \hline
\end{tabular}

The second research question addressed the relationship between compliance-gaining strategies and verbal aggressiveness and argumentativeness. Canonical correlation was performed between the set of predisposition communication variables and the set of compliance-gaining strategies. The predispositional variables included argumentativeness and verbal aggression. The compliance-gaining strategies set consisted of the previously described 16 strategies.

The canonical analysis resulted in two significant roots (Wilks lambda $=.4045, p<.001$, $\mathrm{Rc}=.63$; and Wilks lambda $=.3758, p<.001, \mathrm{Rc}=.5709$ ). Overall, communication argumentativeness and verbal aggressiveness were positively associated with the reported use of compliance-gaining strategies. Table 2 reports the structure and function coefficients for each root.

The first canonical function was composed predominantly of a positively-weighted verbal aggressiveness component and to a much less extent argumentativeness, while the second variate consists of positive loadings on guilt, threat, bargaining, debt, aversive stimulation and warning (those strategies posting loadings below 3 are not discussed for the purpose of this paper). 
TABLE 2

Canonical Component Loadings

\begin{tabular}{lcc}
\hline \hline & $\begin{array}{c}\text { Function 1 Structure } \\
\text { Coefficient }\end{array}$ & $\begin{array}{c}\text { Function 2 Structure } \\
\text { Coefficient }\end{array}$ \\
\hline SET A & .33 & .94 \\
Argumentativeness & .99 & -.05 \\
Verbal Aggressiveness & & \\
SET B &. $.33^{*}$ &. .03 \\
Ingratiation & .10 & -.16 \\
Promise & $.42^{*}$ & .14 \\
Debt & .11 & .11 \\
Esteem & .07 & $.43^{*}$ \\
Allurement & $.40^{*}$ & $.31^{*}$ \\
Aversive Stimulation & $.41^{*}$ &. $.45^{*}$ \\
Threat & $.47^{*}$ & .12 \\
Guilt & $.33^{*}$ & .26 \\
Warning & -.09 & .23 \\
Altruism & .15 & $.33^{*}$ \\
Direct Request & .11 & .19 \\
Explanation & .10 & $.41^{*}$ \\
Hinting &. .06 &. $.37^{*}$ \\
Deceit & -.19 & .27 \\
Empathetic & $.43^{*}$ & .20 \\
Bargaining & & \\
\hline \hline \& 05 & & \\
\hline
\end{tabular}

The second canonical function was composed of argumentativeness and to a much lesser degree negative-weighted verbal aggressiveness. The compliance-gaining strategies of allurement, hinting, and aversive stimulation were positively loaded and deceit and warning were negatively loaded. The interpretation of this canonical suggests that battered women higher on verbal aggressiveness and lower on argumentativeness report using very distinct strategies as do those women who score higher on argumentativeness and lower on verbal aggressiveness.

\section{DISCUSSION}

This study investigated the types of compliance-gaining strategies battered women reported using in their disputes with their batterers that resulted in violence. ${ }^{3}$ The findings presented suggest that battered women most frequently use indirect strategies. That is, those strategies that are less confronting and are derived from indirect power bases. Aversive stimulation (i.e., pouting, sulking, crying) and ingratiation (i.e., manipulation in the form of affection or favor-doing) were the top two strategies most frequently reported by battered women. These strategies are characterized by Johnson (1976) as subservient forms of gaining power that are often characterized as "traditional women strategies." These findings lend support to Walker's (1984) work. In Walker's interviews with battered women, she found that most of these women tried to prevent the abuse by trying to pacify their husbands or accommodate them in any way possible in attempt to prevent his anger. This study, (although it relied on self-report measure) as in Walker's study, found that these attempts did not prevent the violence from occurring.

Such strategies as direct request or warning were reported as the least frequently used by battered women. These strategies inherently rely on direct power bases. For example, to warn an individual requires the source to have some power to punish or remove some type of reward. Battered women in this study were unemployed (approximately $70 \%$ ), with young children who rely 
heavily upon their husbands for support, thus these women may feel that they have little direct power.

The canonical correlation revealed that battered women higher in verbal aggressiveness and lower in argumentativeness reported using specific strategies. These strategies are: guilt, bargaining, debt, threat, aversive stimulation, waming and to a lesser extent, ingratiation. This finding supports previous research such as Boster's (1985) and Boster, Levine, and Kazoleas (1993) which suggests verbal aggressiveness and argumentativeness are antecedent variables for compliance-gaining strategy selection. Further, these findings propose that battered women, (who tend to feel a sense of helplessness in their spousal relationship) resort to indirect power-based strategies in order to gain compliance. That is, although some battered women may be considered verbally aggressive individuals, they are limited to the type of compliance-gaining strategies they report using. They report selecting strategies that are subservient in nature in an attempt to get their batterer to comply with them.

The second canonical root offers an explanation of the relationships of battered women who are higher in argumentativeness and lower in verbal aggressiveness also reported using specific strategies in order to gain compliance from their batterer. Threat and deceit were negatively correlated to this root, suggesting that these women tend not to use these strategies. Rather, this group of women reported using more allurement, hinting, direct request, and aversive stimulation in attempting to gain compliance from their batterer. These strategies share a power-oriented base. One might assume some degree of power or influence over another in selecting these strategies. Specifically, allurement and direct request tend to be strategies that assume that a person has equal status in the relationship.

Furthermore, the correlation between the communication predisposition variables (argumentativeness and verbal aggression) and compliance-gaining strategies is pertinent in understanding abusive relationship. By understanding the communication messages that occur prior to the abusive act, researchers may begin to offer insight to the problem of violence. It is obvious that spousal abuse is a multifaceted issue. This study attempted to address the complexity of the role of spousal communication and its contribution to domestic violence.

Although the present study relied on self-report data, research (Sabourin, Infante, \& Rudd, 1993) has demonstrated the accuracy of self-perception data in a similar context. A natural extension of this study would be to examine reports from the batterers as well as the battered. In summary, this study provides support for the premise that studying compliance-gaining strategies in abusive relationships is worthy of further investigation. 


\section{NOTES}

1. Some scholars have expressed concern about the contamination of compliance-gaining checklists. Burleson, Wilson, Waltman, Goering, Ely, and Whaley (1988) argue that if subjects' responses can be predicated by a separate group's rating of social appropriateness, the original likelihood ratings are contaminated. In order to check for possible contamination due to social desirability, a separate sample $(n=19)$ of college students enrolled in the interpersonal communication course responded to the strategies used in the present study. Using the social appropriateness measure developed by Burleson, et al. (1988) these participants rated each strategy under an abuse scenario. The rankings for the strategies produced by this procedure were correlated with the rankings based on the likelihood of use for our abused women sample. The results of a Spearson correlation $(r=$ -.02 ) indicated that likelihood of use was correlated with social appropriateness in the present study.

Second, Burleson, et al. (1988) contend that contaminated likelihood ratings are indicated by (a) high mean ratings, and (b) extraordinarily small variances. Inspection of Table 1, however, reveals that ten of the sixteen means are around the theoretical mean for each item (i.e., 3.5). Moreover, the highest and lowest likelihood ratings are not extreme. The standard deviations reported in Table 1 are reasonable (range 1.42 - 1.88) given a sixpoint scale. Overall, it does not appear that social appropriateness/desirability influenced participants' reports of use in the present study.

Perhaps, the lack of evidence for a social appropriateness confound is related to our use of checklist. Our use of the checklist is different from the manner in which it was used in past studies. This study is unique in several ways. First, the participants in this study asked to recall their actual behavior rather than responding to a hypothetical situation. Secondly, the population being studied is a specific sample which is different from previous studies that used college students. While we agree with Boster's suggestion of relying on behavioral data, it is difficult, if not impossible, to observe compliance attempts during abusive episodes. Thus, this study is limited to recall data and its limitation.

2. For complete description contact the first author.

3. For comparison purposes, we examined the college women who reported being in nonviolent relationships. Fifty women in the nonviolent group reported using different compliance-gaining strategies. Nonviolent group reported using more hinting $(\mathrm{mf}=3.6)$ and altruism $(\mathrm{mf}=2.45)$ and less warning $(\mathrm{mf}=1.75)$, deceit $(\mathrm{mf}=1.95)$, and allurement $(\mathrm{mf}=1.94)$. Although these findings indicated that women in nonviolent relationships use different compliance-gaining strategies than women in violent relationships, the differences in education, income, age and number of children for the two groups greatly complicates the interpretation of this finding. 


\section{REFERENCES}

Boster, F. J. (1985). Argumentation, interpersonal communication, persuasion, and the process(es) of compliance-gaining use. In J. R. Cox, M. O. Sillars, \& G. B. Walkers (Eds.), Argument and social practice: Proceedings of the fourth SCA/AFA conference on argumentation (pp. 578-590). Annandale, VA: Speech Communication Association.

Boster, F. J., \& Levine, T. R. (1988). Individual differences and compliance-gaining message selection: The effects of verbal aggressiveness, argumentativeness, dogmatism, and negativism. Communication Research Reports, 5, 114-119.

Boster, F. J., Levine, T., \& Kazoleas, D. (1993). The impact of argumentativeness and verbal aggressiveness on strategic diversity and persistence in compliance-gaining behavior. Communication Quarterly, 41, 405-414.

Boster, F. J., Stiff, J. B., \& Reynolds, R. A. (1985). Do persons respond differently to inductivelyderived and deductively-derived lists of compliance-gaining message strategies? A reply to Wiseman and Schenck-Hamlin. Western Journal of Speech Communication, 49, 177 187.

Burleson, B. R., Wilson, S. R., Waltman, M. S., Goering, E. M., Ely, T. K., \& Whaley, B. B. (1988). Item desirability effects in compliance-gaining research. Human Communication Research, $14,429-486$.

Chandler, T. A. (1986). A profile of interaction in acute battering incidents. Unpublished doctoral dissertation, Purdue University, West Lafayette, IN.

Chandler, T. A. (1988, April). Perceptions of verbal and physical aggression in interpersonal violence. Paper presented at the Eastern Communication Association meeting, Baltimore, MD.

Cody, M. J., \& McLaughlin, M. L. (1980). Perceptions of compliance-gaining situations: A dimensional analysis. Communication Monographs, 47, 132-148.

Cody, M. J., McLaughlin, M. L., \& Jordan, W. J. (1980). A multidimensional scaling of three sets of compliance-gaining strategies. Communication Quarterly, 28, 34-46.

Dillard, J. P. (1988). Compliance-gaining message-selection: What is our dependent variable? Communication Monographs, 55, 102-109.

Ericsson, K. A., \& Simon, H. A. (1980). Verbal reports as data. Psychological Review, 87, 215-251.

Falbo, T. (1977). Multidimensional scaling of power strategies. Joumal of Personality and Social Psychology, 38(8), 537-547.

Fitzpatrick, M. A., \& Winke, J. (1979). You always hurt the ones you love: Strategies and tactics in interpersonal conflict. Communication Quarterly, 27, 3-11.

Infante, D. A., Anderson, C. M., Martin, M. M., Herington, A. D., \& Kim, J. (1990). Relations among the perceived communication traits and compliance-gaining strategies of superiors, and subordinates' satisfaction and commitment. Paper presented at the Speech Communication Association Convention, Chicago, IL.

Infante, D. A., Chandler, T. A., \& Rudd, J. E. (1989). Test of an argumentative skill deficiency model of interspousal violence. Communication Monographs, 56, 163-175.

Infante, D. A., Chandler, T. A., Rudd, J. E., \& Shannon, E. A. (1990). Verbal aggression in violent and nonviolent marital disputes. Communication Quarterly, 38, 361-371.

Infante, D. A., \& Rancer, A. S. (1982). A conceptualization and measure of argumentativeness. Journal of Personality Assessment, 46, 72-80.

Infante, D. A., Trebing, J. D., Shepherd, P. E., \& Seeds, D. E. (1984). The relationship of argumentativeness to verbal aggression. The Southern Speech Communication Journal, 50, 67-77.

Infante, D. A., \& Wigley, C. J. (1986). Verbal aggressiveness: An interpersonal model and measure. Communication Monographs, 53, 61-69. 
Johnson, P. (1976). Women and power: Toward a theory of effectiveness. Journal of Social Issues, 32(3), 99-109.

Marwell, G., \& Schmitt, D. R. (1967). Dimensions of compliance-gaining behavior: An empirical analysis. Sociometry, 30(4), 350-364.

Miller, G. R., Boster, F., Roloff, M., \& Seibold, D. (1977). Compliance-gaining message strategies: A typology and some findings concerning effects of situational differences. Communication Monographs, 44, 37-51.

Rancer, A. S., \& Infante, D. A. (1985). Relations between motivation to argue and the argumentativeness of adversaries. Communication Quarterly, 33, 209-218.

Rancer, A. S., Baukus, R. A., \& Infante, D. A. (1985). Relations between argumentativeness and belief structures about arguing. Communication Education, 34, 37-47.

Rancer, A. S., \& Niemasz, J. (1988, April). The influence of argumentativeness and verbal aggressiveness in intrafamily violence. Paper presented to the Eastern Communication Association meeting, Baltimore, MD.

Sabourin, T. C., Infante, D. A., \& Rudd, J. E. (1993). Verbal aggression in marriages: A comparison of violent, distressed but nonviolent, and nondistressed couples. Human Communication Research, 20, 245-267.

Walker, L. E. (1984). The battered women syndrome. New York: Springer.

Wiseman, R. L., \& Schenck-Hamlin, W. (1981). A multidimensional scaling validation of an inductively-derived set of compliance-gaining strategies. Communication Monographs, 48, 252-270. 


\section{APPENDIX 1 \\ The Argumentativeness Scale \\ 10-Item Version}

1. I worry he will form a negative impression of me.

2. I am energetic and enthusiastic when arguing conflicting or controversial issues with him.

3. I enjoy a good argument over a conflicting or controversial issue with him.

4. I am happy when I keep an argument from happening.

5. I enjoy defending my views on an issue.

6. I get nervous and upset after arguing with him.

7. I consider an argument an intellectual challenge.

8. I am unable to think of effective points during an argument.

9. I have the ability to do well in arguments with him.

10. I try to avoid arguments with him.

The Verbal Aggression Scale

10-Item Version

1. I am extremely careful to avoid attacking his intelligence when attacking his ideas.

2. I use insults to soften him when he is very stubborn.

3. I try very hard to avoid having him feel badly about himself when trying to influence him.

4. I attack his character.

5. I try to make him feel good about himself even when his ideas are stupid

6. I lose my temper and say rather strong things to him when he will not budge on a matter of importance.

7. I get a lot of pleasure out of telling him off when he insults me

8. When attacking his ideas I try not to damage his self-concept.

9. I make a great effort not to offend him when trying to convince him of my position.

10. I yell and scream when nothing else seems to work. 
Copyright of Communication Research Reports is the property of Routledge, Ltd.. The copyright in an individual article may be maintained by the author in certain cases. Content may not be copied or emailed to multiple sites or posted to a listserv without the copyright holder's express written permission. However, users may print, download, or email articles for individual use. 